\title{
Research
}

\section{Bereavement research: methodological issues and ethical concerns}

\author{
Margaret Stroebe Department of Clinical Psychology, Utrecht University, Utrecht, Wolfgang Stroebe \\ Department of Social and Organizational Psychology, Utrecht University, Utrecht and Henk Schut Department of \\ Clinical Psychology, Utrecht University, Utrecht
}

\begin{abstract}
Principles of conducting research in the field of bereavement are introduced. The review focuses on issues of design and methodology, and considers ethical concerns, particularly in view of the fact that bereaved people are frequently in acute grief when scientific study is conducted. Accurate assessment is fundamental, and requires methodologically stringent procedures. The merits and disadvantages of different types of investigation are considered, the often-neglected need for control groups is described, and quantitative versus qualitative methodological approaches are reviewed. Also considered are biases due to selection and limits on generalizability. Understanding of ethical matters arising in this field of research is essential for the conduct of worthwhile research, and involves methodological sophistication. Palliative Medicine 2003; 17: 235-240
\end{abstract}

Key words: bereavement; ethics; grief; methodology; research design

\section{The case of gender differences}

The death of a loved person is a normal part of life, one that at first sight may not be an obvious topic for scientific investigation. Is it not enough to rely on human insight and clinical experience to provide the right sort of support for bereaved people and to understand grief and grieving? In fact, there are a variety of arguments that can be given in support of an empirical, scientific approach, from both societal and theoretical points of view, but let us instead take an apparently simple example that turns out to be more complex than expected. This will be useful for understanding the guidelines for conducting research we discuss below.

Counsellors and therapists typically encounter a larger proportion of widows needing support than widowers. It would seem fair to conclude from this - as not only healthcare professionals but also some researchers have done - that widows are more vulnerable and in need of counselling than widowers, on the loss of a partner. Is this really the case? It we examine research, we learn that the widow to widower ratio is frequently as high as $4: 1,{ }^{1}$ because women live longer than men, tend to marry men

Address for correspondence: Margaret Stroebe, Department of Clinical Psychology, Utrecht University, Heidelberglaan 1, 3584 CS Utrecht, The Netherlands.

E-mail: m.stroebe@fss.uu.nl older then themselves, and remarry after widowhood less frequently than men. Thus, according to such epidemiological data, even if, comparatively speaking, widowers were to be as distressed as widows, fewer of them would actually look for support. Furthermore, psychological studies have indicated that women have higher rates of depression than men. ${ }^{2,3}$ It has also been shown that women cope with stressful life events such as bereavement in different ways, for example by confronting and expressing such negative emotions more than is the case for men. ${ }^{4-6}$ Perhaps widowers also adopt other ways of coming to terms with their grief than showing their distress or help seeking. We cannot accept the original conclusion that widows are more vulnerable without looking into such possibilities in a systematic, scientific manner.

How do we reach an accurate picture of the risk? One approach would be to investigate the relative rates of symptomatology of widowed males and females compared with the rates for married men and women. Such ratios control for the total numbers of persons in each of these groups. Under such conditions, it becomes evident that the conclusion stated at the outset (widows suffer more) was indeed spurious. Large-scale, methodologically sophisticated studies have shown that, relative to married men, widowers have higher rates of depression than do widows compared with married women. ${ }^{7}$ 
This example has also demonstrated an underlying interest in bereavement research, namely, to discover precisely - using good methodology - who among the bereaved is at risk of poor adjustment. Bereavement is associated with suffering for many, and with extreme mental and physical health consequences for some persons. What precisely are the psychological and physical health effects, how long do they last, who suffers from them most and why? What underlying processes can be identified that lead us to greater understanding of differences in adjustment? The history of bereavement research shows that scientists began first with systematic examination of the nature and symptoms of grief, including the health effects. From an early focus on the grieving individual, recent research has begun to include interpersonal issues as well, including social risk factors, the effectiveness of intervention, and the consequences of bereavement on social networks. Most recently, there has been investigation of processes underlying the manifestations and phenomena associated with bereavement. This has been accompanied by finer-grained theorizing and more sophisticated methodologies. ${ }^{8}$

Having sketched the type of difficulties that bereavement researchers are up against, and indicated the general scope of the research area, we can address the central theme: What comprises worthwhile research in the field of bereavement? ? $^{*}$ We focus on the conduct of research, and therefore on design and methodology, but we also highlight ethical concerns - for it must not be forgotten that bereaved people are highly vulnerable. ${ }^{\dagger}$

\section{Research design}

It became evident from the example given above that accurate assessment of grief phenomena may be obscured by wrong methodology. But what comprises sound empirical research? First we review different types of investigation to provide an overview of the scope and type of study in the bereavement field, identify the most useful strategies and pinpoint design and methodological pitfalls.

Choice of data collection methods: large-scale surveys versus in-depth interviews

Two main data collection methods are found in bereavement research, large-scale surveys and in-depth interviews, which frequently go hand in hand respectively with cross-sectional and longitudinal, and with retrospective versus prospective designs. Surveys are frequently epide-

\footnotetext{
* Although focus in this article is on psychological research, an interdisciplinary approach (e.g., use of epidemiological or medical information) is frequently adopted, and the principles can generally be more broadly applied too.

For a general review of statistical problems, see Reference 9.
}

miological investigations of representative samples, while interviews are typically conducted with small and nonrepresentative samples of bereaved (and nonbereaved) subjects. Choice of data collection methods depends on the goals and priorities of the project.

There are advantages and disadvantages inherent in the survey design. For example, there is usually the advantage that subjects are not recruited because they are bereaved, and are therefore less likely to give researchers the responses they think they want. For example, widowed respondents would not be interviewed in their status and role as 'widowed', thus avoiding demand characteristics, since they are simply part of a large survey that notes their marital status. In principle, this would be feasible in small-scale in-depth studies, but generally the latter studies are set up and introduced as investigations of bereavement reactions. Likewise, sampling bias through self-selection is circumvented. Finally, data are usually collected from representative samples, permitting more generalization than small-sample studies. However, there are also disadvantages. Comparisons are frequently cross-sectional. That is, they assess only at one point in time. Although it may be possible to compare persons who have lost a loved person either say at one, two, three or more years previously, there is nevertheless the problem that there may be extraneous differences between these cross-sectional cohorts (e.g., an epidemic or disaster). Another potential shortcoming is that the bereaved are not always subdivided according to the duration of their bereavement in such surveys, thus preventing comparison of the short (usually most intense) versus long term effects. Furthermore, such studies do not allow one to keep track of those who remarry, thus potentially biasing the statistics (perhaps the more depressed find it harder to remarry). Most critical is that they rarely gather in-depth information on psychological process or state variables. Few national surveys ask detailed questions about grief and grieving.

Many bereavement researchers are interested in a more fine-grained analysis of predictors of health outcome and processes of adjustment. For this, in-depth interviews with small samples of recently bereaved individuals are more appropriate. This type of design permits a careful matching with nonbereaved controls. It has the advantage that variables of theoretical interest can be examined in detail. Furthermore, there is often the possibility of a longitudinal design, in which respondents can be reinterviewed periodically, enabling a detailed account of the course of grief over time. For example, it is possible to make causal statements about the impact of a particular cognitive process (e.g., the attribution that there is responsibility for the death) on outcome (persistent high scores on a grief inventory). Occasionally, it is possible to obtain prospective, rather than retrospective prebereavement information as well. ${ }^{10}$ This has the 
advantage that subjective assessments (e.g., the quality of a marriage before the death of a partner) are not colored by the fact of bereavement (e.g., idealization, or anger at being left alone). It is probably true to say that a prospective, in-depth, longitudinal, design that can include matched nonbereaved control groups, is the most powerful design available in bereavement research.

Such designs suffer too, though, from weaknesses. They are time consuming and expensive, which limits the number of respondents that can be interviewed. Refusal rates are often high. Furthermore, an issue that has been given very little attention by researchers, concerns the dual role of researchers as interviewer and 'therapist'. Interviews in which the bereaved person describes his/her loss and its impact could have a therapeutic effect, thereby influencing the very process that it set out to study. ${ }^{11}$ Another bias in response could be a result of demand characteristics. To admit to well-being and no grieving (even to oneself, but more so to an interviewer) goes against the norm of indicating love for the deceased person.

Some of the shortcomings mentioned above could be circumvented by adopting a postal questionnaire procedure. This would of course be easier and less time consuming. However, such a procedure also needs careful consideration. It is less personal, and it is harder to monitor the effect of answering written questions. As we will describe later, the researcher has an ethical obligation to ensure that no harm is done by his/her research to a respondent. ${ }^{12}$ Many researchers choose for a 'mixed' strategy, interviewing at the first point of measurement, and asking respondents if they would be willing to participate in written follow ups.

\section{Control groups}

A control group is a group not exposed to the experience or factors whose impact the researcher wishes to study. The need for and choice of a control group depends on the hypotheses being tested and the inferences that the authors wish to draw. For example, if we want to examine the comparative vulnerability of widows and widowers to depression, we need a control group to establish what the baseline rates of depression are, for some nonbereaved persons will also be depressed. Sometimes, control groups are omitted in scientific investigations. Investigators choose instead to assess the impact of bereavement on health (or other variable) by comparing health status at different points in time in relation to the loss event. But such a design does not allow for control over numerous sources of invalidity, such as maturation (aging effects), history (an external event, unrelated to the personal loss), or testing (filling out tests repeatedly may have an influence on test scores).

There are, though, some research questions that can indeed be investigated without inclusion of a nonbe- reaved control group. One might be interested in differences between bereaved groups. For example, one might be interested in differences between fathers and mothers in ways of coping with the loss of their child (e.g., how much they focus on the loss), and in how a discrepancy may affect their long-term adjustment. Here, one could compare couples who are very different in the amount of confrontation with those who are very similar and make differential predictions about such things as wellbeing and marital satisfaction. However, it must be remembered that such a study tells us nothing about how differential coping of men and women in general affects wellbeing or marital satisfaction. Comparison with nonbereaved controls makes no sense if bereavementspecific symptoms (e.g., yearning for the deceased; feeling his/her presence; (lack of) acceptance of the loss) are studied, rather than depression, or somatic symptoms. What we must be particularly careful about in the latter type of investigation - that is, if the investigation does not include nonbereaved comparison groups - is to interpret population effects as bereavement-specific risk factors. For example, if widows of lower socio-economic standing are found to have poorer health than those of higher socio-economic status, this could simply reflect the fact that lower socio-economic status persons in general are less healthy".

It is not easy to select an appropriate comparison group, that is, one that is equivalent to the bereaved on all-imp ortant dimensions other than the event of bereavement. Large-scale surveys have to use 'adjusted' or 'specific' (e.g. age- and gender-specific) rather than 'crude' rates. This is done to overcome such problems as the fact that, for example, a married sample is likely to be much younger than the bereaved (and age is associated with deteriorating health) which could be an alternative explanation for differences between these groups. It is also important to address a matching problem that is specific to bereavement research, namely: which nonbereaved group to choose? We have used the example of married controls in the context of spousal bereavement, because these are more similar to widowed than single persons with respect to age and selection into marriage, and because, unlike the divorced, they have remained in a marital relationship.

Measurement issues: quantitative versus qualitative It is difficult either to conceptualize or to measure even the most fundamental aspects surrounding grief, for it is a complex emotional syndrome. Nevertheless, methodological techniques have recently expanded to enable more sophisticated analyses of grief and grieving. The broad

\footnotetext{
* Relative risk calculation is an important scientific concern In practice, though, assessment of absolute risk may at times be more relevant (e.g., to provide care for large actual numbers of lower social class bereaved, and women, in poor health).
} 
range of approaches are characteristic of the disciplinary affiliations of researchers, ranging from clinical psychology, gerontology, and sociology to physiology, epidemiology and medicine. Although the techniques are not mutually exclusive, the phenomena and manifestations of grief have typically been assessed in one of two ways: either quantitatively or qualitatively. ${ }^{*}$

Quantitative investigation of grief reactions involves the use of self-report rating scales focusing specifically on personal reactions to bereavement. While early research was characterized by the use of nonvalidated measures, in recent years much effort has gone into examining the psychometric properties of the measures used, and even to comparing different measures according to their psychometric properties. ${ }^{16}$ Various types of instruments are now available for the quantitative assessment of grief responses, and it is important to select a measure for a research project that is both reliable and valid. There are advantages to using the quantitative method. ${ }^{16}$ It allows for a fine-grained measurement of grief responses in different groups of bereaved persons. It enables diagnosis of potentially 'at-risk' persons for complicated courses of grief. It enables a tracking of grief symptoms over time or following intervention. However, standardized questionnaires also have limitations. For example, important dimensions of grief and grieving may be missed simply because the researchers did not include certain topics in a questionnaire.

Qualitative research provides an alternative paradigm for bereavement research, one that has the potential to add depth to the assessment of the grieving process, through the use of a broad range of techniques for study design, data collection, analysis, and interpretation. These techniques are also reviewed by Neimeyer and Hogan. ${ }^{16}$ Qualitative approaches explore socially and personally constructed realities, with the goal to discover unique and common perspectives of the persons being studied, rather than to generate incontestable 'facts'. Interviews, use of case studies, content analysis and ethnography all fall within this category. Such approaches are suited to revealing the unique meanings that underlie the reactions of bereaved individuals or cultural groups. It is easy to see that these methods have the potential to broaden and deepen the study of bereavement. One of the main disadvantages, however, is that the descriptive orientation limits the extent to which they can provide causal explanations for grief phenomena, assess the efficacy of grief interventions, or

\footnotetext{
* For discussion of measurement issues concerning ways of coping see Reference 13, interpersonal processes, see Reference 14 , or the measurement of the efficacy of intervention for bereaved persons, see Reference 15 .
}

identify correlates of complicated grief. Furthermore, reliability and validity of the measures used in qualitative assessment remain a major concern.

Quantitative and qualitative research complement each other in the bereavement field. There are good reasons to argue for methodological pluralism. ${ }^{16}$ In our view, there is a lot to be said for quantitative evaluation to be preceded by qualitative, in-depth assessment. In this way, the advantages of each approach can be realized, and the disadvantages to some extent overcome.

Selection and generalizability: attrition and dropout How representative of the bereaved in general are those who participate in research studies? As noted above, we are accessing a vulnerable group. Some persons may choose to participate as a way of sharing and coming to terms with their loss experience. Others may hope that their contribution will further understanding for bereaved persons as a group. Some may refuse because they are too upset to be interviewed, or fear that this might increase their grief. Others may refuse because they have 'got over it', and do not want to look back. Such selection issues are particularly critical in bereavement research, because participation decisions and grief reactions are likely to be closely related, and because it is precisely these grief reactions that we are trying to assess.

Again, the gender example illustrates this concern. We conducted an investigation of the distress of widowed interview participants and refusers. ${ }^{17}$ The latter had been willing to fill out a postal questionnaire but did not want a face-to-face interview. There was no general difference in depression: the interviewed and postal responders had similar levels of depression. This suggested that we could, indeed, generalize from our interview study to make inferences about the larger population of widowed persons. However, closer inspection showed that depression affected willingness to participate differently for males and females. Whereas widowers who were less depressed agreed to participate in an interview, the opposite was the case for widows. This shows that researchers must take such selection biases in sampling into account. Similarly, characteristics of dropouts in longitudinal research need to be monitored and reported. For example, it is not sufficient to compare participants with dropouts on socio-demographic characteristics. As illustrated above, we would also need to know such things as their status on a depression scale: have we lost the most distressed from the sample?

It is not easy to take account of selection and dropout biases in studies of bereavement because, by definition, these persons do not want to be studied. There are ethical reasons too, then, why it is so hard to solve these selection issues. All we can sometimes do is to be aware of potential biases and assess or estimate their potential effect on the results as best we can. 


\section{Ethical concerns}

Doing good research is fundamental in any area, but needs particular emphasis when conducted with bereaved individuals. As a researcher, one is potentially an intruder into the world of the bereaved, and one must, for example, fully respect the decision of a bereaved person not to participate in a research project. This reflects the most basic ethical principle: a researcher must protect the rights, dignity and wellbeing of participants. While this is the overriding principle, there are specific issues to be taken into account too. Here we can only highlight these: The researcher must become fully acquainted him/herself with ethical guidelines and principles prior to starting a research project, as explained elsewhere. ${ }^{12,18-20}$

One specific matter illustrates the type of ethical issue that researchers always have to consider carefully: How and how soon - can we approach bereaved people to participate in research? Many of the channels that might be relatively acceptable to both bereaved persons and researchers have drawbacks, particularly due to selection effects. For example, approaching through a church community selects religious persons. Using hospital records has the disadvantage of excluding persons whose spouses did not die under hospital care. Using bereavement support organizations selects those who have chosen to, and stayed in, support programs for the bereaved. And yet, to use obituaries or other official sources seems hard hearted and dubious. There is no easy solution. A carefully worked-out procedure is necessary. This must allow the bereaved person the chance to refuse at the outset or to withdraw at any point during the study and it must assure anonymity and confidentially - which must be scrupulously observed.

The question 'how soon?' is also not easily answered, and great variation can be seen in the period after bereavement when different researchers think it fit to begin their investigation. A strategy that we have adopted when starting a new study has been to run a pilot investigation with a longer-duration bereaved sample in the particular subgroup (e.g., parents of a deceased child). This is also a way to develop sensitivity on a number of issues when beginning a new research project. Then it is possible, for example, to ask respondents to think back: how soon after bereavement would they have felt it appropriate for us to approach them?

It is necessary to be aware of the complexity of many decisions in this research area. As researchers, we have an obligation to examine the efficacy of bereavement intervention programs, for it is unethical to offer help that has not been proved to be helpful. Many programs are of doubtful efficacy (for a review, see Reference 15). Yet, how do we go about such evaluation? In a study of the evaluation of bereavement intervention, can we really assign bereaved individuals randomly to control condi- tions? While a 'waiting list control' strategy is often used, this still means that some bereaved are waiting longer for needed help (it may be advisable to exclude extreme cases from the investigation, and offer all of these help early on). What happens if a participant in a nonintervention study is severely distressed and in evident need of therapy? Although it intervenes in the bereavement process that one is measuring and introduces a design flaw, in our view the interests of the bereaved person come before design purity. This touches on a related ethical concern. The bereavement researcher must have adequate procedures in place should a participant become distressed after sharing his/her emotions in the context of the study. If they are not themselves skilled counsellors or therapists, they must establish a backup system of professional help.

\section{Conclusions}

To return to our question: what comprises worthwhile research in the field of bereavement? Here we have concentrated on two of three central criteria. We have considered design and methodological adequacy, and we have highlighted ethical responsibility. A third criterion, the theoretical and societal relevance of a research project, was beyond our scope, although it has been implicit in many of the above discussions. In fact, the three criteria are interrelated parts of worthwhile research. For example, methodologically unsound or irrelevant (theoretical and/or applied) research is not ethical (one is wasting the time and energy of bereaved respondents).

Contemporary research in the field of bereavement can take advantage of recent improvements in research design and measurement, including diversity of methods, a broad range of approaches, and better-validated measures. This goes together with a greater awareness of ethical matters, attempts at developing guidelines for bereavement research, and moving toward a more systematic approach to ethical considerations. ${ }^{12}$ The scope of bereavement research has broadened remarkably in recent years. ${ }^{8}$ Particularly given such expansion, it is important to evaluate research on the basis of the principles outlined above.

\section{References}

1 US Department of Health and Human Services, Public Health Service. Vital statistics of the United States, 1985. Washington, DC: US Government Printing Office, 1985.

2 Derlega V, Metts S, Petronio S, Margulis S. Selfdisclosure. Newbury Park, CA: Sage, 1993. 
3 Pennebaker J, Roberts T. Toward a his and hers theory of emotion: gender differences in visual perception. $J$ Soc Clin Psychol 1992; 11: 199-212.

4 Nolen-Hoeksema S, Larson J. Coping with loss. Mahwah, NJ: Lawrence Erlbaum, 1999.

5 de Ridder D. Gender, stress, and coping: do women handle stressful situations differently from men? In Sherr $\mathrm{L}$, St. Lawrence $\mathrm{J}$ eds. Women, health and the mind. Chichester, England: Wiley, 2000.

6 Schut H, Stroebe M, de Keijser J, van den Bout J. Gender differences in the efficacy of grief counseling. $\mathrm{Br}$ J Clin Psychol 1997; 36: 63-72.

7 Stroebe M, Stroebe W, Schut H. Gender differences in adjustment to bereavement: an empirical and theoretical review. Rev Gen Psychol 2001; 5 :62-83.

8 Stroebe M, Hansson R, Stroebe W, Schut H eds. Handbook of bereavement research: consequences, coping, and care. Washington, DC: American Psychological Association, 2001.

9 Schnurr P. Satatistical review: an approach to common methodological and statistical problems. J. Trauma Stress 1998; 11: 405-12.

10 Gallagher-Thompson D, Futterman A, Farberow N, Thompson L, Peterson J. The impact of spousal bereavement on older widows and widowers. In Stroebe $\mathrm{M}$, Stroebe W, Hansson $\mathrm{H}$ eds. Handbook of bereavement: Theory, research, and intervention. New York: Cambridge University, 1993.

11 Caserta M, Lund D, Dimond M. Assessing interviewer effects in a longitudinal study of bereaved elderly adults. J. Gerontol 1985; 40: 637-40.

12 Cook A. The dynamics of ethical decision making in bereavement research. In Stroebe $M$, Hansson R, Stroebe W, Schut $\mathrm{H}$ eds. Handbook of bereavement research: consequences, coping, and care. Washington, DC: American Psychological Association, 2001.

13 van Heck G, de Ridder D. Assessment of coping with loss: dimensions and measurement. In Stroebe $M$, Hansson R, Stroebe W, Schut H eds. Handbook of bereavement research: consequences, coping, and care. Washington, DC: American Psychological Association, 2001.

14 Nadeau J. Meaning making in family bereavement: a family systems approach. In Stroebe M, Hansson R, Stroebe W, Schut $\mathrm{H}$ eds. Handbook of bereavement research: consequences, coping, and care. Washington, DC: American Psychological Association, 2001.

15 Schut H, Stroebe M, van den Bout J, Terheggen M. The efficacy of bereavement interventions: determining who benefits. In Stroebe M, Hansson R, Stroebe W, Schut H eds. Handbook of bereavement research: consequences, coping, and care. Washington, DC: American Psychological Association, 2001.

16 Neimeyer R, Hogan N. Quantitative or qualitative? Measurement issues in the study of grief. In Stroebe M, Hansson R, Stroebe W, Schut H eds. Handbook of bereavement research: consequences, coping, and care. Washington, DC: American Psychological Association, 2001.

17 Stroebe M, Stroebe W. Who participates in bereavement research? A review and empirical study. Omega-J Death and Dying 1989; 20: 1-29.

18 Parkes C. Guidelines for conducting ethical bereavement research. Death Stud 1995; 19 :171-81.

19 Rosenblatt P. Ethics of qualitative interviewing with grieving families. Death Stud 1995; 19: 139-55.

20 Sales B, Folkman S. Ethical issues in the conduct of research with human participants. Washington, DC: American Psychological Association, 2001. 